$\checkmark$ Just as we are all concerned over the lack of opportunity for many youths in our inner cities, the Fairmont Heights High School (Capitol Heights, MD) has established a Biotechnology Center. The Center functions as a magnet school for for some twenty schools in the greater Washington DC area. Approximately 150 students are currently enrolled in an intensive four year science program designed to prepare them for college study in the biological sciences.

And while many of us may be "short" on funds for new equipment, for them funds are essentially non-existent. They would greatly appreciate donations iof journals/books on SEM topics and sample specimens, both from the physical and biological sciences, to assist students in research projects and in building microscopy skills.

AND they critically need a Sputter Coater and a Critical Point Dryer. Should you have either that you would care to donate, we expect that you would receive a tax deduction. Or if you have either available and need (modest) payment, kindly contact Microscopy Today as we expect that we can find sponsors.

Should you be able to provide help, please contact:

Mr. Joe Kroto, Biotechnology Center

Fairmont Heights High School

1401 Nye Street

Capital Hights, MD 20743
Tel.: (301)773-1200

Fax: (301)773-5177 $\checkmark$ Dr. John Bradley, recently of McCrone Associates, Inc, has joined MVA, Inc. (Norcross GA). John will be providing analytical electron microscopy services for state of the art materials characterization, supplementing MVA's established capabilities in scanning electron microscopy, light microscopy and micro-FT-IR spectroscopy.

$\checkmark$ A new predoctoral fellowship program aimed at preparing researchers to use chemical approaches to biological problems is being launched by the National Institute of General Medical Sciences (NIGMS). The new program is designed to encourage chemistry, pharmaceutical chemistry, and medicinal chemistry facility to participate more in NIGMS Ph.D. training efforts - with the goal "to provide chemists with training in biological science so that they can foresee the biological potential of the compounds with which they work and can apply chemical principles for the design of new compounds to answer biological questions"

$\checkmark$ A new six-axes, high resolution specimen stage for SEMs has been developed by E. Fjeld Co. (Billerica MA). The sixth degree of motion provides an additional tilt axis of $+1-90^{\circ}$ from side to side in relationship to the primary tilt of the stage. The primary tilt towards the secondary detector is $-45^{\circ}$ to $+90^{\circ}$. The $X$ and $Y$ translations are typically $100-125 \mathrm{~mm}$ of motion, with continuous $Z$ and $360^{\circ}$ of rotation.

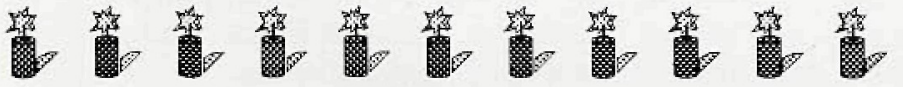 24

The management and staff of DIATOME congratulate EMSA on their 50th anniversary.

As our part in their celebration, DIATOME is pleased to announce that it will have a fish bowl raffle and will choose one winner of a diamond knife of their choice each day at the EMSA 1992 exhibition to be held this coming August in Boston. This raffle will be in addition to the DIATOME standard award that is offered each year at EMSA. For more information, please call (215)646-1478.

The July and August issues of Microscopy Today will be combined in a single, special EMSA '92 Conference issue.

In addition to mailing to our readership (which is expected to approach 10,000 individuals in the U.S. with an interest in microscopy) for receipt prior to the Conference, we will hand out copies from our booth at the Conference.

Featured in this issue will be a section on what is "New and/or Interesting in Microscopy - EMSA '92) similar to what we did at PITTCON'92. - - Ed.

\title{
Overloaded? Understaffed?
}

Let us help you augment and compliment your current laboratory services.

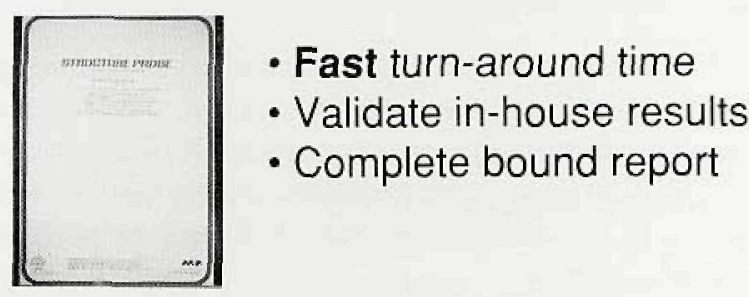

- SEM - TEM -AEM

- XPS (ESCA) - AES

- PLM I Ion Beam Thinning

- Metallography

-WDS

- Cryo Ultramicrotomy

\section{STRUGTURE PROBE}

\section{Call Toll-Free 1-800-2424-SPI}

Convenient locations in and near New York, Long Island, Philadelphia, and Connecticut. 